$11-1-2016$

\title{
Estimation of Population Mean on Recent Occasion under Non-Response in h-Occasion Successive Sampling
}

Anup Kumar Sharma

Indian School of Mines, Dhanbad, India, aksharma.ism@gmail.com

Garib Nath Singh

Indian School of Mines, Dhanbad, India

Follow this and additional works at: http://digitalcommons.wayne.edu/jmasm

Part of the Applied Statistics Commons, Social and Behavioral Sciences Commons, and the Statistical Theory Commons

\section{Recommended Citation}

Sharma, Anup Kumar and Singh, Garib Nath (2016) "Estimation of Population Mean on Recent Occasion under Non-Response in hOccasion Successive Sampling," Journal of Modern Applied Statistical Methods: Vol. 15 : Iss. 2 , Article 12. DOI: $10.22237 /$ jmasm/1478002200

Available at: http://digitalcommons.wayne.edu/jmasm/vol15/iss2/12 


\section{Estimation of Population Mean on Recent Occasion under Non- Response in h-Occasion Successive Sampling}

\section{Cover Page Footnote}

A. K. Sharma and G. N. Singh Department of Applied Mathematics, Indian School of Mines, Dhanbad-826004, India. E-mail: gnsingh_ism@yahoo.com and aksharma.ism@gmail.com 


\section{Estimation of Population Mean on Recent Occasion under Non-Response in $h$-Occasion Successive Sampling}

\author{
Anup Kumar Sharma \\ Indian School of Mines \\ Dhanbad, India
}

\author{
Garib Nath Singh \\ Indian School of Mines \\ Dhanbad, India
}

In this article, an attempt has been made to study on general estimation procedures of population mean on recent occasion when non-response occurs in $h$-occasion successive sampling. Suggested estimators have advantageously influenced the estimation procedures in the presence of non-response. Detailed properties of the suggested estimation procedures have been examined and compared with the estimation process of the same circumstances but in the absence of non-response. Empirical studies have been carried out to demonstrate the performances of the estimates and suitable recommendations have been made.

Keywords: $\quad$ Non-response, successive sampling, study variable, variance

\section{Introduction}

Successive sampling was developed for estimation of population parameters on recent point of time (occasion), when the population parameters changes over successive points of time (occasion). It is a sampling method to provide reliable and fruitful estimates of population parameters over different desire points of time (occasion). Jessen (1942) initiated a technique with the help of past information to provide the effective estimates on current occasion in two-occasion successive sampling. Later, this technique was extended by Yates (1949), Patterson (1950), Tikkiwal (1951), Eckler (1955), Rao and Graham (1964), Gupta (1979), Binder and Hidiroglou (1988), Kish (1998), McLaren and Steel (2000), Singh, Kennedy and $\mathrm{Wu}$ (2001), Steel and McLaren (2002) among others. Sen (1971, 1973) applied this theory in designing the estimators of population mean using information on two or more auxiliary variables which was readily available on

A. K. Sharma is in the Department of Applied Mathematics. Email at: aksharma.ism@gmail.com. G. N. Singh is in the Department of Applied Mathematics. Emailat:gnsingh_ism@yahoo.com . 


\section{ESTIMATION OF POPULATION MEAN UNDER NON-RESPONSE}

previous occasion in two-occasion successive sampling. Singh, Singh and Shukla (1991), Singh and Singh (2001) made an efficient use of auxiliary variable on current occasion and subsequently Singh (2003) uses this methodology for $h$ occasion successive sampling in estimation of current population mean.

In many situations, information on an auxiliary variable may be readily available on the first as well as on the second occasion. Utilizing the auxiliary information on both occasions, Feng and Zou (1997), Biradar and Singh (2001), Singh (2005), Singh and Karna (2009), Singh and Prasad (2010), Singh, Prasad, and Karna (2011), Singh, Majhi, Maurya, and Sarma (2015) and Singh and Sharma $(2014$, 2015) have proposed several estimators of population mean on current (second) occasion in two-occasion successive sampling.

Non-response is a common problem almost encountered in all sample surveys and successive sampling is more prone to this problem because of its repetitive nature. For example, in agriculture yield surveys, it might be possible that crop on certain plots are destroyed due to some natural calamities or disease so that yield on these plots are impossible to be measured. Hansen and Hurwitz (1946) suggested a method of sub sampling of non-respondents to address the problems of non-response in mail surveys. Later on Cochran (1977) and Okafor and Lee (2000) extended this technique for the case when besides the information on character under study, information is also available on one auxiliary character. More recently, Choudhary, Bathla, and Sud (2004), Singh and Priyanka (2007), and Singh and Kumar (2008) used the Hansen and Hurwitz (1946) technique for the estimation of population mean on current occasion in context of sampling on two occasions.

Motivated with the above arguments and using Hansen and Hurwitz (1946) method, the aim of the present work is to suggest the estimation procedure for population mean at $h^{\text {th }}$ (recent) occasion when the non-response occurs on $h^{\text {th }}$ occasion, $(h-1)^{\text {th }}$ (previous) occasion and simultaneously on both $h^{\text {th }}$ and $(h-1)^{\text {th }}$ occasions in $h$-occasion successive (rotation) sampling. The properties of the proposed estimation procedure have been examined and compared with the similar estimation but under complete response. Empirical studies are carried out and suitable recommendations have been made.

\section{Notations}

Let $U=\left(U_{1}, U_{2},--, U_{\mathrm{N}}\right)$ be the finite population of $N$ units, which has been sampled over $h$ occasions. The character under studies are denoted by $y_{h}$ and $y_{h-1}$ on the $h^{\text {th }}$ and $(h-1)^{\text {th }}$ occasions respectively. Assume that the non-response occur 


\section{SHARMA \& SINGH}

on $h^{\text {th }}$ occasion, $(h-1)^{\text {th }}$ occasion and simultaneously on both $h^{\text {th }}$ and $(h-1)^{\text {th }}$ occasions, so that the population can be divided into two classes, those who will respond at the first attempt and those who will not. Let the sizes of these two classes be $N_{h}$ and $N^{*}{ }_{h}$ on the $h^{\text {th }}$ occasion and the corresponding sizes on $(h-1)^{\text {th }}$ occasion be $N_{h-1}$ and $N^{*}{ }_{h-1}$. Let a simple random sample (without replacement) of size $n$ be selected on the $h^{\text {th }}$ occasion which consist of $n_{h}^{\prime}=n \lambda_{h}$ units common to the units observed on the $(h-1)^{\text {th }}$ occasion and $n_{h}^{\prime \prime}=n \mu_{h}$ units drawn afresh on the $h^{\text {th }}$ occasion i.e. $n=n_{h}^{\prime}+n_{h}^{\prime \prime}$. Here $\lambda_{h}$ and $\mu_{h}\left(\lambda_{h}+\mu_{h}=1\right)$ are the fractions of matched and unmatched samples, respectively, on the $h^{\text {th }}$ occasion. The values of $\lambda_{h}$ and $\mu_{h}$ should be chosen optimally. Assume that in the unmatched portion of the sample on the $h^{\text {th }}$ occasion $n_{h}^{\prime \prime}$ units respond and $n_{h 2}^{\prime \prime}$ units do not respond. Let $n_{h 2 s}^{\prime \prime}$ denote the size of sub sample drawn from the non-response class in the unmatched portion of the sample on the $h^{\text {th }}$ occasion and their response collected by direct contact or interview. Similarly, $n_{h 1}^{\prime}$ units respond and $n_{h 2}^{\prime}$ units do not respond in the sample of matched units and let $n_{h 2 s}^{\prime}$ denote the size of sub sample drawn from the non-response class in the matched portion of the sample on the $h^{\text {th }}$ occasion and their response collected by direct contact or interview. Following are the list of notations, which are considered for their further use:

$\bar{Y}_{h}:$

$\bar{y}_{h}^{\prime}:$

$\bar{y}_{h}^{\prime \prime}:$

$\rho_{h, h-1}: \quad \quad$ The correlation between the study variables $y_{h}$ and $y_{h-1}$.

$S_{h y}^{2}:$

$W_{h-1}^{*}=\frac{N_{h-1}^{*}}{N}: \quad$ The proportion of non-responding units in the population on the $W_{h}^{*}=\frac{N_{h}^{*}}{N}$ :

The population mean of the study variable $y_{h}$ on the $h^{\text {th }}$ occasion.

The sample mean of the study variable based on $n_{h}^{\prime}$ units common to the units observed on the $(h-1)^{\text {th }}$ occasion.

The sample mean of the study variable based on $n_{h}^{\prime \prime}$ units drawn afresh on the $h^{\text {th }}$ occasion. $(h-1)^{\text {th }}$ occasion.

The proportion of non-responding units in the population on the $h^{\text {th }}$ occasion. 


\section{ESTIMATION OF POPULATION MEAN UNDER NON-RESPONSE}

$$
\begin{aligned}
& f\left(\frac{n}{N}\right): \quad \text { The sampling fraction. } \\
& f_{1}=\frac{n_{h 2}^{\prime}}{n_{h 2 s}^{\prime}} \\
& f_{2}=\frac{n_{h 2}^{\prime \prime}}{n_{h 2 s}^{\prime \prime}}
\end{aligned}
$$

\section{Formulation of Estimator}

For estimating the population mean $\bar{Y}$ on the $h^{\text {th }}$ occasion, a sample mean and a regression type estimator are suggested. First is the Hansen and Hurwitz (1946) type estimator, say $\omega_{h}^{\prime \prime}$, which is based on $n_{h}^{\prime \prime}$ sample units drawn afresh on $h^{\text {th }}$ occasion such that out of these $n_{h}^{\prime \prime}$ units, $n_{h 1}^{\prime \prime}$ units respond and remaining $n_{h 2}^{\prime \prime}\left(=n_{h}^{\prime \prime}-n_{h 1}^{\prime \prime}\right)$ units do not respond. Hence, $\omega_{h}^{\prime \prime}$ is defined as

$$
\omega_{h}^{\prime \prime}=\bar{y}_{h}^{\prime \prime *}
$$

where

$$
\bar{y}_{h}^{\prime \prime *}=\frac{n_{h 1}^{\prime \prime} \bar{y}_{1}^{\prime \prime}+n_{h 2}^{\prime \prime} \bar{y}_{h 2 s}^{\prime \prime}}{n_{h}^{\prime \prime}}
$$

The second estimator is based on the sample of size $n_{h}^{\prime}$, which is common to the units observed on the $(h-1)^{\text {th }}$ occasion. Because non-response is occurred on the previous occasion, therefore, again Hansen and Hurwitz (1946) type estimator are considered. The second estimator, $\omega_{h}^{\prime}$, for estimating the population mean on $h^{\text {th }}$ occasion is a regression type estimator, and is defined as

$$
\omega_{h}^{\prime}=\bar{y}_{h}^{\prime *}+\beta_{h, h-1}\left(\omega_{h-1}-\bar{y}_{h-1}^{\prime *}\right)
$$

where 


$$
\bar{y}_{h}^{* *}=\frac{n_{h 1}^{\prime} \bar{y}_{h 1}^{\prime}+n_{h 2}^{\prime} \bar{y}_{h 2}^{\prime}}{n_{h}^{\prime}}, \bar{y}_{h-1}^{\prime *}=\frac{n_{h 1}^{\prime} \bar{y}_{(h-1) 1}^{\prime}+n_{h 2}^{\prime} \bar{y}_{(h-1) 2}^{\prime}}{n_{h}^{\prime}}
$$

and $\beta_{h, h-1}$ is population regression coefficient between the study variable $y_{h}$ and $y_{h-1}$.

The resulting estimator $\omega_{h}$ is a convex linear combination of the estimators $\omega_{h}^{\prime \prime}$ and $\omega_{h}^{\prime}$. The estimator $\omega_{h}$ is defined as

$$
\omega_{h}=\varphi_{h} \omega_{h}^{\prime \prime}+\left(1-\varphi_{h}\right) \omega_{h}^{\prime}
$$

where $\varphi_{h}\left(0 \leq \varphi_{h} \leq 1\right)$ is the unknown constant to be determined under certain criterion.

Remark 1: $\quad$ For estimating the mean on $h^{\text {th }}$ occasion the estimator $\omega_{h}^{\prime \prime}$ is suitable, which implies that more belief on $\omega_{h}^{\prime \prime}$ could be shown by choosing $\varphi_{h}$ as 1 (or close to 1), while for estimating the change from one occasion to the next, the estimator $\omega_{h}^{\prime}$ could be more useful so $\varphi_{h}$ might be chosen as 0 (or close to 0 ). For asserting both the problems simultaneously, the suitable (optimum) choice of $\varphi_{h}$ is required.

Remark 2: $\quad$ (i) Assume that the correlation between variables observed on two occasions, more than one occasion apart is zero. (ii) For practical application the population regression coefficient will be estimated by their respective sample estimates.

\section{Properties of the Estimator $\omega_{h}$}

Because $\omega_{h}^{\prime \prime}$ and $\omega_{h}^{\prime}$ are sample mean and difference type estimators respectively, they are unbiased for population mean $\bar{Y}_{h}$. Therefore, the resulting estimator $\omega_{h}$ defined in equation (3) is also an unbiased estimator of $\bar{Y}_{h}$. The variance of the estimator $\omega_{h}$ is shown in following theorem.

Theorem 1: Variance of the estimator $\omega_{h}$ to the first order of approximations is obtained as 


\section{ESTIMATION OF POPULATION MEAN UNDER NON-RESPONSE}

$$
V\left(\omega_{h}\right)=\varphi_{h}^{2} V\left(\omega_{h}^{\prime \prime}\right)+\left(1-\varphi_{h}\right)^{2} V\left(\omega_{h}^{\prime}\right)+2 \varphi_{h}\left(1-\varphi_{h}\right) C\left(\omega_{h}^{\prime \prime}, \omega_{h}^{\prime}\right)
$$

where

$$
\begin{gathered}
V\left(\omega_{h}^{\prime \prime}\right)=\left[\frac{1}{n_{h}^{\prime \prime}}\left\{1+W_{h}^{*}\left(f_{2}-1\right)\right\}-\frac{1}{N}\right] S_{h y}^{2} \\
V\left(\omega_{h}^{\prime}\right)=\left[\frac{1}{n_{h}^{\prime}}\left\{1+W_{h-1}^{*}\left(f_{1}-1\right)\right\}\left(1-\rho_{h, h-1}^{2}\right)+\frac{\varphi_{h-1}}{n_{h-1}^{\prime \prime}} \rho_{h, h-1}^{2}-\frac{1}{N}\right] S_{h y}^{2}
\end{gathered}
$$

and

$$
C\left(\omega_{h}^{\prime \prime}, \omega_{h}^{\prime}\right)=-\frac{1}{N} S_{h y}^{2}
$$

Remark 3: Following Hansen and Hurwitz (1946) technique, some variances which are used in Theorem 1, are evaluated as given below:

$$
\begin{aligned}
V\left(\bar{y}_{h}^{\prime \prime^{*}}\right) & =V\left[E\left(\bar{y}_{h}^{\prime \prime *} \mid n_{h 1}^{\prime \prime}, n_{h 2}^{\prime \prime}\right)\right]+E\left[V\left(\bar{y}_{h}^{\prime \prime} \mid n_{h 1}^{\prime \prime}, n_{h 2}^{\prime \prime}\right)\right] \\
& =V\left(\bar{y}_{h}^{\prime \prime}\right)+E\left[\frac{n_{h 2}^{\prime \prime}}{n_{h}^{\prime \prime 2}}\left(f_{2}-1\right) S_{h y}^{2}\left(n_{h 2}^{\prime \prime}\right)\right] \\
& =\left(\frac{1}{n_{h}^{\prime \prime}}-\frac{1}{N}\right) S_{h y}^{2}+\frac{\left(f_{2}-1\right)}{n^{\prime \prime}} S_{h y}^{2}\left(N_{h}^{*}\right) \frac{N_{h}^{*}}{N}
\end{aligned}
$$

where $S_{h y}^{2}\left(N_{h}^{*}\right)$ is the population variance of non response class on $h^{\text {th }}$ occasion. Further we assume that $S_{h y}^{2}\left(N_{h}^{*}\right)=S_{h y}^{2}$, and hence

$$
V\left(\bar{y}_{h}^{\prime \prime \prime}\right)=\left[\left(\frac{1}{n_{h}^{\prime \prime}}-\frac{1}{N}\right)+\frac{W_{h}^{*}\left(f_{2}-1\right)}{n_{h}^{\prime \prime}}\right] S_{h y}^{2}
$$

Similarly 


$$
\begin{gathered}
V\left(\bar{y}_{h}^{\prime *}\right)=\left[\left(\frac{1}{n_{h}^{\prime}}-\frac{1}{N}\right)+\frac{W_{h-1}^{*}\left(f_{1}-1\right)}{n_{h}^{\prime}}\right] S_{h y}^{2} \\
V\left(\bar{y}_{h-1}^{\prime *}\right)=\left[\left(\frac{1}{n_{h}^{\prime}}-\frac{1}{N}\right)+\frac{W_{h-1}^{*}\left(f_{1}-1\right)}{n_{h}^{\prime}}\right] S_{(h-1) y}^{2}
\end{gathered}
$$

where

$$
f_{1}=\frac{n_{h 2}^{\prime}}{n_{h 2 s}^{\prime}} ; f_{2}=\frac{n_{h 2}^{\prime \prime}}{n_{h 2 s}^{\prime \prime}}
$$

\section{Minimum Variance of the Estimator $\omega_{h}$}

Substituting the values of variances and covariance from equations (5), (6) and (7) in equation (4) we have the expression of the exact variance of the proposed estimator $\omega_{h}$. Now, minimize the variance of $\omega_{h}$, which is shown in equation (4). Define a function $f(x, y)$, where the variables $x$ and $y$ are interpreted as $\varphi_{h}$ and $\mu_{h}$ respectively, which represents the expression of the variance of $\omega_{h}$ given in equation (4). Thus, variance of $\omega_{h}$ is reduce to following equation

$$
f(x, y)=\frac{S}{n}\left[\frac{x^{2}}{y} \Delta_{2}+(1-x)^{2}\left(\frac{\Delta_{1}}{1-y}+\gamma\right)-f\right]
$$

where

$$
\begin{gathered}
S=S_{h y}^{2}, \quad \alpha=1-\rho_{h, h-1}^{2}, \quad \gamma=t_{h-1} \rho_{h, h-1}^{2}, \quad \Delta_{1}=\alpha+W_{h-1}^{*}\left(f_{1}-1\right) \alpha, \\
\Delta_{2}=1+W_{h}^{*}\left(f_{2}-1\right), t_{h-1}=\frac{\varphi_{h-1}}{\mu_{h-1}}, \quad \mu_{h}=1-\lambda_{h}, \quad \text { and } f=\frac{n}{N} .
\end{gathered}
$$

To find the minimum variance, we differentiate the equation (11) with respect to $x$ and $y$ respectively and then equate to zero,

$$
\frac{x}{y} \Delta_{2}=\frac{1-x}{1-y}\left[\Delta_{1}+\gamma(1-y)\right]
$$




\section{ESTIMATION OF POPULATION MEAN UNDER NON-RESPONSE}

and

$$
\frac{x}{y} \sqrt{\Delta_{2}}=\frac{1-x}{1-y} \sqrt{\Delta_{1}}
$$

From equations (12) and (13),

$$
y=1-\sqrt{\Delta_{1}}\left(\sqrt{\Delta_{2}}-\sqrt{\Delta_{1}}\right) \gamma^{-1}
$$

Again, from equations (13) and (14), if

$$
\frac{y}{x}=1+\left(\sqrt{\Delta_{2}}-\sqrt{\Delta_{1}}\right)^{2} \gamma^{-1}
$$

then

$$
t_{h}=\left[1+r_{h} t_{h}^{-1}\right]^{-1}=\frac{x}{y}
$$

where

$$
r_{h}=\left(\sqrt{\Delta_{2}}-\sqrt{\Delta_{1}}\right)^{2}(1-\alpha)^{-1}
$$

Because the values of $\alpha$ depend on the values of correlation. Therefore, $\alpha \geq 0$ and consequently $r_{h}$ is real. After iteration,

$$
t_{h}=\left[1-\sum_{j=1}^{h} \prod_{k=j}^{h} r_{k}\right]^{-1}
$$

Hence, minimum variance of $\omega_{h}$ is obtained from equations (11) and (12) which is as follows

$$
V\left(\omega_{h}\right)_{\mathrm{opt}}=f(x, y)_{\mathrm{opt}}=\frac{S}{n}\left[t_{h} \Delta_{2}-f\right]
$$


SHARMA \& SINGH

\section{Special Cases}

Case 1: When non-response occurs only on $(h-1)^{\text {th }}$ (previous) occasion.

For the case when non-response occurs only on $(h-1)^{\text {th }}$ occasion, the estimator for population mean $\bar{Y}_{h}$ on recent occasion may be structured as

$$
\omega_{h}^{*}=\varphi_{h}^{*} \tau_{h}^{\prime \prime}+\left(1-\varphi_{h}^{*}\right) \omega_{h}^{\prime}
$$

where $\tau_{h}^{\prime \prime}=\bar{y}_{h}^{\prime \prime}$ and $\omega_{h}^{\prime}=\bar{y}_{h}^{\prime *}+\beta_{h, h-1}\left(\omega_{h-1}^{*}-\bar{y}_{h-1}^{*}\right) . \varphi_{h}^{*}$ is unknown constant to be determined so as to minimize the variance of the estimator $\omega_{h}^{*}$.

\section{Properties of the estimator $\omega_{h}^{*}$}

Because $\tau_{h}^{\prime \prime}$ and $\omega_{h}^{\prime}$ are sample mean and difference type estimators respectively, they are unbiased for population mean $\bar{Y}_{h}$. Therefore, the resulting estimator $\omega_{h}^{*}$ is defined in equation (20) is also unbiased estimator of $\bar{Y}_{h}$.

Theorem 2: $\quad$ variance of the estimator $\omega_{h}^{*}$ is obtained as

$$
V\left(\omega_{h}^{*}\right)=\varphi_{h}^{* 2} V\left(\tau_{h}^{\prime \prime}\right)+\left(1-\varphi_{h}^{*}\right)^{2} V\left(\omega_{h}^{\prime}\right)+2 \varphi_{h}^{*}\left(1-\varphi_{h}^{*}\right) C\left(\tau_{h}^{\prime \prime}, \omega_{h}^{\prime}\right)
$$

where

$$
\begin{aligned}
& V\left(\tau_{h}^{\prime \prime}\right)=\left(\frac{1}{n_{h}^{\prime \prime}}-\frac{1}{N}\right) S_{h y}^{2} \\
& V\left(\omega_{h}^{\prime}\right)=\left[\frac{1}{n_{h}^{\prime}}\left\{1+W_{h-1}^{*}\left(f_{1}-1\right)\right\}\left(1-\rho_{h, h-1}^{2}\right)+\frac{\varphi_{h-1}^{*}}{n_{h-1}^{\prime \prime}} \rho_{h, h-1}^{2}-\frac{1}{N}\right] S_{h y}^{2}
\end{aligned}
$$

and 
ESTIMATION OF POPULATION MEAN UNDER NON-RESPONSE

$$
C\left(\tau_{h}^{\prime \prime}, \omega_{h}^{\prime}\right)=-\frac{1}{N} S_{h y}^{2}
$$

\section{Minimum Variance of the estimator $\omega_{h}^{*}$}

Similarly, represent the expression of the variance of $\omega_{h}^{*}$ in equation (21) as

$$
f^{*}\left(x^{*}, y^{*}\right)=\frac{S}{n}\left[\frac{x^{* 2}}{y^{*}}+\left(1-x^{*}\right)^{2}\left(\frac{\Delta_{1}}{1-y^{*}}+\gamma\right)-f\right]
$$

To find the minimum variance,

$$
\begin{gathered}
\frac{x^{*}}{y^{*}}=\frac{1-x^{*}}{1-y^{*}}\left[\Delta_{1}+\gamma\left(1-y^{*}\right)\right] \\
\frac{x^{*}}{y^{*}}=\frac{1-x^{*}}{1-y^{*}} \sqrt{\Delta_{1}}
\end{gathered}
$$

From equations (26) and (27),

$$
y^{*}=1-\sqrt{\Delta_{1}}\left(1-\sqrt{\Delta_{1}}\right) \gamma^{-1}
$$

Further,

$$
\begin{aligned}
& \frac{y^{*}}{x^{*}}=1+\left(1-\sqrt{\Delta_{1}}\right)^{2} \gamma^{-1} \\
& t_{h}^{*}=\left[1+r_{h}^{*} t_{h-1}^{*-1}\right]^{-1}=\frac{x^{*}}{y^{*}}
\end{aligned}
$$

where

$$
r_{h}^{*}=\left(1-\sqrt{\Delta_{1}}\right)^{2}(1-\alpha)^{-1}
$$




$$
t_{h}^{*}=\left[1+\sum_{j=1}^{h} \prod_{k=j}^{h} r_{k}^{*}\right]^{-1}
$$

From (25) and (26) minimum variance of $\omega_{h}^{*}$ is expressed as

$$
V\left(\omega_{h}^{*}\right)_{\mathrm{opt}}=f^{*}\left(x^{*}, y^{*}\right)_{\mathrm{opt}}=\frac{S}{n}\left[t_{h}^{*}-f\right]
$$

\section{Case 2: When non-response occurs only on $h^{\text {th }}$ (recent) occasion}

The estimator for the population mean $\bar{Y}_{h}$ on recent occasion for this case may be given as

$$
\omega_{h}^{* *}=\varphi_{h}^{* *} \omega_{h}^{\prime \prime}+\left(1-\varphi_{h}^{* *}\right) \tau_{h}^{\prime}
$$

where $\omega_{h}^{\prime \prime}$ is defined in equation (1) and $\tau_{h}^{\prime}=\bar{y}_{h}^{\prime}+\beta_{h, h-1}\left(\omega_{h-1}^{* *}-\bar{y}_{h-1}^{\prime}\right)$ and $\varphi_{h}^{* *}$ is unknown constant to be determined so as to minimize the variance of the estimator $\omega_{h}^{* *}$.

\section{Properties of the estimators $\omega_{h}^{* *}$}

Because $\omega_{h}^{\prime \prime}$ and $\tau_{h}^{\prime}$ are sample mean and difference type estimators respectively, they are unbiased for population mean $\bar{Y}_{h}$. Therefore, the resulting estimator $\omega_{h}^{* *}$ defined in equation (34) is also unbiased estimator of $\bar{Y}_{h}$.

Theorem 3: $\quad$ Variance of estimators $\omega_{h}^{* *}$ is obtained as

$$
V\left(\omega_{h}^{* *}\right)=\varphi_{h}^{* * 2} V\left(\omega_{h}^{\prime \prime}\right)+\left(1-\varphi_{h}^{* * *}\right)^{2} V\left(\tau_{h}^{\prime}\right)+2 \varphi_{h}^{* *}\left(1-\varphi_{h}^{* *}\right) C\left(\omega_{h}^{\prime \prime}, \tau_{h}^{\prime}\right)
$$

where $V\left(\omega_{h}^{\prime \prime}\right)$ is shown in equation (5),

$$
V\left(\tau_{h}^{\prime}\right)=\left[\frac{1}{n_{h}^{\prime}}\left(1-\rho_{h, h-1}^{2}\right)+\frac{\varphi_{h-1}^{* *}}{n_{h-1}^{\prime \prime}} \rho_{h, h-1}^{2}-\frac{1}{N}\right] S_{h y}^{2}
$$




\section{ESTIMATION OF POPULATION MEAN UNDER NON-RESPONSE}

and

$$
C\left(\Delta_{h}^{\prime \prime}, \tau_{h}^{\prime}\right)=-\frac{1}{N} S_{h y}^{2}
$$

Minimum Variance of the estimator $\omega_{h}^{* *}$

The expression of the variance of $\omega_{h}^{* *}$ shown in equation (35) is reduced to the following form

$$
f^{* * *}\left(x^{* * *}, y^{* * *}\right)=\frac{S}{n}\left[\frac{x^{* * 2}}{y^{* * *}} \Delta_{2}+\left(1-x^{* * *}\right)^{2}\left(\frac{\alpha}{1-y^{* *}}+\gamma\right)-f\right]
$$

To find the minimum variance,

$$
\begin{gathered}
\frac{x^{* *}}{y^{* *}}=\frac{1-x^{* *}}{1-y^{* *}}\left[\alpha+\gamma\left(1-y^{* *}\right)\right] \\
\frac{x^{* * *}}{y^{* * *}} \sqrt{\Delta_{2}}=\frac{1-x^{* *}}{1-y^{* * *}} \sqrt{\alpha}
\end{gathered}
$$

From equations (39) and (40)

$$
y^{* *}=1-\sqrt{\alpha}\left(\sqrt{\Delta_{2}}-\sqrt{\alpha}\right) \gamma^{-1}
$$

then

$$
\begin{gathered}
\frac{y^{* *}}{x^{* *}}=1+\left(\sqrt{\omega_{2}}-\sqrt{\beta}\right)^{2} \gamma^{-1} \\
t_{h}^{* *}=\left[1+r_{h}^{* * t_{h-1}^{* *-1}}\right]^{-1}=\frac{x^{* * *}}{y^{* *}}
\end{gathered}
$$

where 


$$
\begin{gathered}
r_{h}^{* *}=\left(\sqrt{\Delta_{2}}-\sqrt{\alpha}\right)^{2}(1-\alpha)^{-1} \\
t_{h}^{* *}=\left[1+\sum_{j=1}^{h} \prod_{k=j}^{h} r_{k}^{* *}\right]^{-1}
\end{gathered}
$$

Thus, from (38) and (39) minimum variance of $\Delta_{h}^{* *}$ is obtained as

$$
V\left(\omega_{h}^{* *}\right)_{\mathrm{opt}}=f^{* * *}\left(x^{* *}, y^{* * *}\right)_{\mathrm{opt}}=\frac{S}{n}\left[t_{h}^{* *} \Delta_{2}-f\right]
$$

\section{Efficiency Comparison}

To examine the loss in precision of the estimators $\omega_{h}, \omega_{h}^{*}$ and $\omega_{h}^{* *}$ due to nonresponse, the percent relative loss in precision of estimator $\omega_{h}, \omega_{h}^{*}$ and $\omega_{h}^{* *}$ with respect to the estimator $\tau_{h}$, have been computed for different choices of $\rho_{h, h-1}$. The estimator $\tau_{h}$ is defined under the similar circumstances as the estimator $\omega_{h}$ but in the absence of non-response. Hence the estimator $\tau_{h}$ is given as

$$
\tau_{h}=\varphi_{h} \tau_{h}^{\prime \prime}+\left(1-\varphi_{h}\right) \tau_{h}^{\prime}
$$

where $\tau_{h}^{\prime \prime}=\bar{y}_{h}^{\prime \prime}, \quad \tau_{h}^{\prime}=\bar{y}_{h}^{\prime}+\beta_{h, h-1}\left(\tau_{h-1}-\bar{y}_{h-1}^{\prime}\right)$ and $\psi_{h}$ is unknown constant to be determined by the minimization of the variance of $\tau_{h}$.

Following Sukhatme, Sukhatme, Sukhatme, and Asok (1984) the optimum variance of $\tau_{h}$ is given by

$$
V\left(\tau_{h}\right)_{\mathrm{opt}}=\frac{S}{n}\left[\hat{t}_{h}-f\right]
$$

where $\hat{t}_{h}=\left[1+\sum_{j=1}^{h} \prod_{k=j}^{h} \hat{r}_{k}\right]^{-1}$ and $\hat{r}_{k}=(1-\sqrt{\alpha})(1+\sqrt{\alpha})^{-1}$. 


\section{ESTIMATION OF POPULATION MEAN UNDER NON-RESPONSE}

Remark 4: $\quad$ To compare the performance of the estimators $\omega_{h}, \omega_{h}^{*}$ and $\omega_{h}^{* *}$ with respect to $\tau_{h}$, the assumptions $W_{h}^{*}=W_{h-1}^{*}$ (say $W^{*}$ ) are introduced. The percent relative losses in precision of the estimators $\omega_{h}, \omega_{h}^{*}$ and $\omega_{h}^{* *}$ with respect to $\tau_{h}$ under their respective optimality conditions are given by

$$
L=\frac{V\left(\omega_{h}\right)_{\mathrm{opt}}-V\left(\tau_{h}\right)_{\mathrm{opt}}}{V\left(\omega_{h}\right)_{\mathrm{opt}}} \times 100 \quad L^{*}=\frac{V\left(\omega_{h}^{*}\right)_{\mathrm{opt}}-V\left(\tau_{h}\right)_{\mathrm{opt}}}{V\left(\omega_{h}^{*}\right)_{\mathrm{opt}}} \times 100
$$

and

$$
L^{* *}=\frac{V\left(\omega_{h}^{* *}\right)_{\mathrm{opt}}-V\left(\tau_{h}\right)_{\mathrm{opt}}}{V\left(\omega_{h}^{* *}\right)_{\mathrm{opt}}} \times 100
$$

The expressions of $\mu_{h(\mathrm{opt})}, \mu_{h(\mathrm{opt})}^{*}, \mu_{h(\mathrm{opt})}^{* *}$ and the percent relative losses are given in terms of the population correlation coefficients. Therefore, they have been computed for different choices of correlation $\rho_{h, h-1}$. Percent relative losses in precision of the estimators $\omega_{h}, \omega_{h}^{*}$ and $\omega_{h}^{* *}$ have been computed for different choices of $f, f_{1}, f_{2}, W_{h}^{*}, W_{h-1}^{*}$ and $\rho_{h, h-1}$.

Presented in Tables $1-3$ are the optimum values of $\mu_{h(\mathrm{opt})}, \mu_{h(\mathrm{opt})}^{*}, \mu_{h(\mathrm{opt})}^{* *}$ and the percent relative losses with respect to $\tau_{h}$. 


\section{SHARMA \& SINGH}

Table 1. Percent relative loss $L$ in precision of $\omega_{h}$ with respect to $\tau_{h}$ for $f=0.1$.

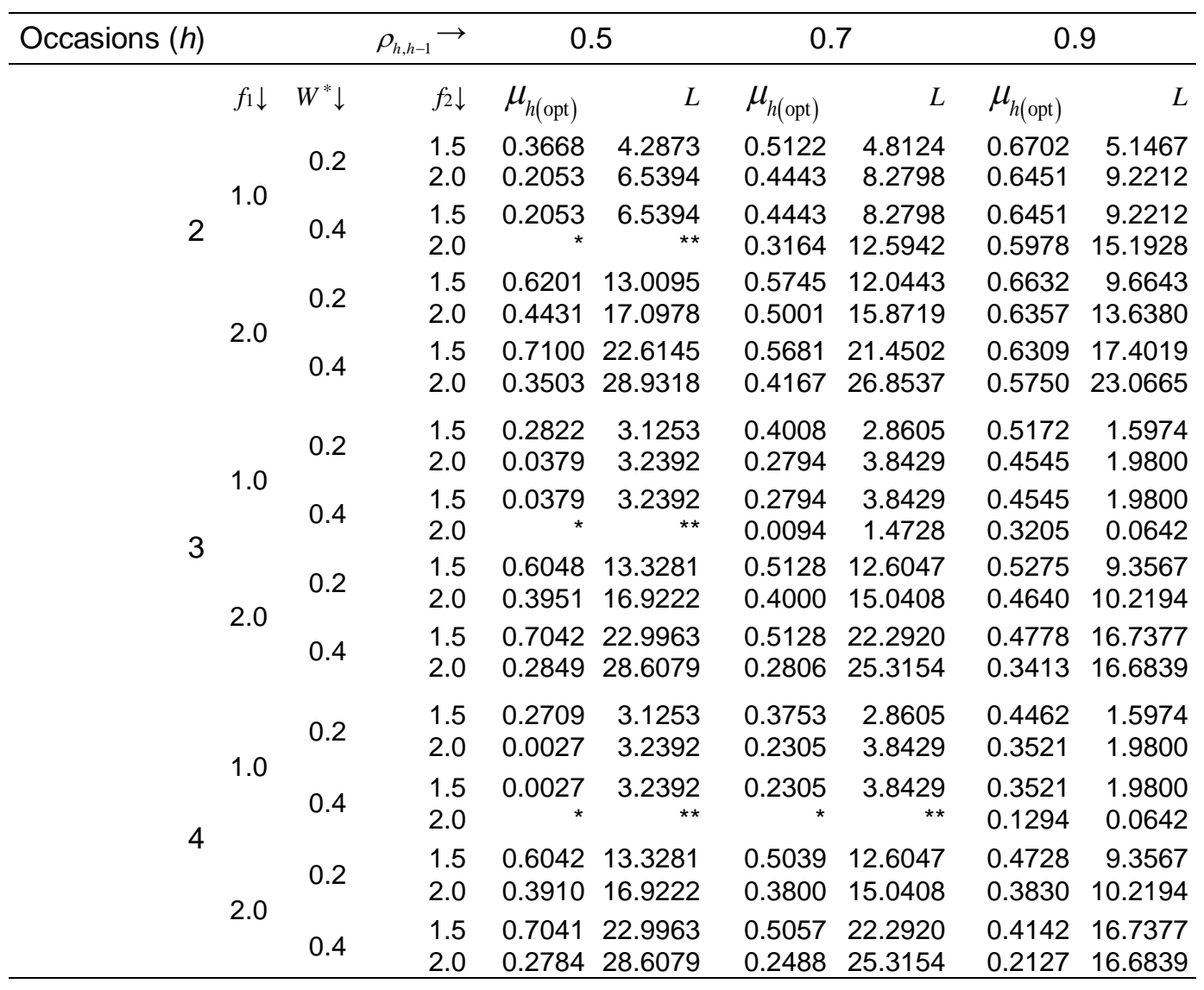

*Note: “*” indicate $\mu_{h(\mathrm{opt})}$ does not exist. 


\section{ESTIMATION OF POPULATION MEAN UNDER NON-RESPONSE}

Table 2. Percent relative loss $L^{*}$ in precision of $\omega_{h}^{*}$ with respect to $\tau_{h}$ for $f=0.1$.

\begin{tabular}{|c|c|c|c|c|c|c|c|c|}
\hline \multirow[t]{2}{*}{ Occasions $(h)$} & \multicolumn{2}{|r|}{$\rho_{h, h-1} \rightarrow$} & \multicolumn{2}{|c|}{0.5} & \multicolumn{2}{|c|}{0.6} & \multicolumn{2}{|c|}{0.8} \\
\hline & $f_{1} \downarrow$ & $W^{*} \downarrow$ & $\mu_{h(\mathrm{opt})}^{*}$ & $L^{*}$ & $\mu_{h(\mathrm{opt})}^{*}$ & $L^{*}$ & $\mu_{h(\mathrm{opt})}^{*}$ & $L^{*}$ \\
\hline 2 & 1.5 & $\begin{array}{l}0.2 \\
0.4\end{array}$ & $\begin{array}{l}0.6668 \\
0.8053\end{array}$ & $\begin{array}{l}3.9706 \\
6.3585\end{array}$ & $\begin{array}{l}0.6163 \\
0.6524\end{array}$ & $\begin{array}{l}3.6895 \\
6.7430\end{array}$ & $\begin{array}{l}0.6936 \\
0.6920\end{array}$ & $\begin{array}{l}2.4170 \\
4.6254\end{array}$ \\
\hline & 2.0 & $\begin{array}{l}0.2 \\
0.4\end{array}$ & 0.8053 & $\begin{array}{r}6.3585 \\
* *\end{array}$ & $\begin{array}{l}0.6524 \\
0.7327\end{array}$ & $\begin{array}{r}6.7430 \\
11.2723\end{array}$ & $\begin{array}{l}0.6920 \\
0.6917\end{array}$ & $\begin{array}{l}4.6254 \\
8.5195\end{array}$ \\
\hline & 1.5 & $\begin{array}{l}0.2 \\
0.4\end{array}$ & $\begin{array}{l}0.6556 \\
0.8032\end{array}$ & $\begin{array}{l}4.3688 \\
6.8491\end{array}$ & $\begin{array}{l}0.5670 \\
0.6188\end{array}$ & $\begin{array}{l}4.6766 \\
8.3301\end{array}$ & $\begin{array}{l}0.5822 \\
0.5882\end{array}$ & $\begin{array}{l}3.8818 \\
7.2990\end{array}$ \\
\hline 3 & 2.0 & $\begin{array}{l}0.2 \\
0.4\end{array}$ & $\begin{array}{r}0.8032 \\
*\end{array}$ & $\underset{* *}{6.8491}$ & $\begin{array}{l}0.6188 \\
0.7196\end{array}$ & $\begin{array}{r}8.3301 \\
13.3894\end{array}$ & $\begin{array}{l}0.5882 \\
0.6024\end{array}$ & $\begin{array}{r}7.2990 \\
13.0285\end{array}$ \\
\hline 4 & 1.5 & $\begin{array}{l}0.2 \\
0.4\end{array}$ & $\begin{array}{l}0.6552 \\
0.8032\end{array}$ & $\begin{array}{l}4.4016 \\
6.8849\end{array}$ & $\begin{array}{l}0.5607 \\
0.6156\end{array}$ & $\begin{array}{l}4.8963 \\
8.6488\end{array}$ & $\begin{array}{l}0.5416 \\
0.5532\end{array}$ & $\begin{array}{l}4.6755 \\
8.6882\end{array}$ \\
\hline 4 & 2.0 & $\begin{array}{l}0.2 \\
0.4\end{array}$ & 0.8032 & $\begin{array}{r}6.8849 \\
* *\end{array}$ & $\begin{array}{l}0.6156 \\
0.7189\end{array}$ & $\begin{array}{r}8.6488 \\
13.7590\end{array}$ & $\begin{array}{l}0.5532 \\
0.5766\end{array}$ & $\begin{array}{r}8.6882 \\
15.2022\end{array}$ \\
\hline
\end{tabular}

*Note "*" indicate $\mu_{h(\mathrm{opt})}^{*}$ does not exist.

Table 3. Percent relative loss $L^{* *}$ in precision of $\omega_{h}^{* *}$ with respect to $\tau_{h}$ for $f=0.1$.

\begin{tabular}{|c|c|c|c|c|c|c|c|c|}
\hline \multirow[t]{2}{*}{ Occasions $(h)$} & \multirow[b]{2}{*}{$f_{2 \downarrow} \downarrow$} & \multirow{2}{*}{$\begin{array}{r}\rho_{h, h-1} \rightarrow \\
W^{*} \downarrow\end{array}$} & \multicolumn{2}{|c|}{0.5} & \multicolumn{2}{|c|}{0.6} & \multicolumn{2}{|c|}{0.7} \\
\hline & & & $\mu_{h(\mathrm{opt})}^{* *}$ & $L^{* *}$ & $\mu_{h(\mathrm{opt})}^{* * *}$ & $\mathrm{~L}^{* * *}$ & $\mu_{h(\mathrm{opt})}^{* *}$ & $L^{* *}$ \\
\hline \multirow[t]{2}{*}{2} & 1.5 & $\begin{array}{l}0.2 \\
0.4\end{array}$ & $\begin{array}{l}0.3668 \\
0.2053\end{array}$ & $\begin{array}{l}4.2873 \\
6.5394\end{array}$ & $\begin{array}{l}0.5122 \\
0.4443\end{array}$ & $\begin{array}{l}4.8124 \\
8.2798\end{array}$ & $\begin{array}{l}0.6702 \\
0.6451\end{array}$ & $\begin{array}{l}5.1467 \\
9.2212\end{array}$ \\
\hline & 2.0 & $\begin{array}{l}0.2 \\
0.4\end{array}$ & 0.2053 & $\underset{* *}{6.5394}$ & $\begin{array}{l}0.4443 \\
0.3164\end{array}$ & $\begin{array}{r}8.2798 \\
12.5942\end{array}$ & $\begin{array}{l}0.6451 \\
0.5978\end{array}$ & $\begin{array}{r}9.2212 \\
15.1928\end{array}$ \\
\hline \multirow{2}{*}{3} & 1.5 & $\begin{array}{l}0.2 \\
0.4\end{array}$ & $\begin{array}{l}0.2822 \\
0.0379\end{array}$ & $\begin{array}{l}3.1253 \\
3.2392\end{array}$ & $\begin{array}{l}0.4008 \\
0.2794\end{array}$ & $\begin{array}{l}2.8605 \\
3.8429\end{array}$ & $\begin{array}{l}0.5172 \\
0.4545\end{array}$ & $\begin{array}{l}1.5974 \\
1.9800\end{array}$ \\
\hline & 2.0 & $\begin{array}{l}0.2 \\
0.4\end{array}$ & 0.0379 & 3.2392 & $\begin{array}{l}0.2794 \\
0.0094\end{array}$ & $\begin{array}{l}3.8429 \\
1.4728\end{array}$ & $\begin{array}{l}0.4545 \\
0.3205\end{array}$ & $\begin{array}{l}1.9800 \\
0.0642\end{array}$ \\
\hline \multirow[b]{2}{*}{4} & 1.5 & $\begin{array}{l}0.2 \\
0.4\end{array}$ & $\begin{array}{l}0.2709 \\
0.0027\end{array}$ & $\begin{array}{l}2.9384 \\
2.4725\end{array}$ & $\begin{array}{l}0.3753 \\
0.2305\end{array}$ & $\begin{array}{l}2.2653 \\
2.2186\end{array}$ & $\begin{array}{l}0.4462 \\
0.3521\end{array}$ & $\begin{array}{l}-0.6762 \\
-3.1638\end{array}$ \\
\hline & 2.0 & $\begin{array}{l}0.2 \\
0.4\end{array}$ & $\begin{array}{r}0.0027 \\
*\end{array}$ & $\begin{array}{r}2.4725 \\
* * \\
\end{array}$ & $\begin{array}{r}0.2305 \\
*\end{array}$ & $\begin{array}{r}2.2186 \\
* *\end{array}$ & $\begin{array}{l}0.3521 \\
0.1294 \\
\end{array}$ & $\begin{array}{r}-3.1638 \\
-13.0652 \\
\end{array}$ \\
\hline
\end{tabular}

*Note: “*” indicate $\mu_{h(\text { opt })}^{* *}$ does not exist. 


\section{SHARMA \& SINGH}

\section{Results}

\section{Behavior of Estimator $\omega_{h}$,}

From Table 1,

(a) For the fixed values of $h, f_{1}, f_{2}$ and $W^{*}$, the value of $\mu_{h(\mathrm{opt})}$ are mostly increased while the values of $L$ are almost decreased when the values of $\rho_{h, h-1}$ are increased.

(b) For the fixed values of $h, f_{1}, W^{*}$ and $\rho_{h, h-1}$, the values of $\mu_{h(\mathrm{opt})}$ decrease while $L$ increases with the increasing value of $f_{2}$. This trend shows the larger fresh sample is required to be replaced on the recent occasion.

(c) For the fixed values of $h, f_{2}, W^{*}$, and $\rho_{h, h-1}$, the values of $\mu_{h(\mathrm{opt})}$ and $L$ are increasing with the increasing values of $f_{1}$.

(d) For the fixed values of $h, f_{1}, f_{2}$ and $\rho_{h, h-1}$, the values of $\mu_{h(\mathrm{opt})}$ almost decrease while $L$ increases with the increasing value of $W^{*}$. This behavior shows that the higher the non-response rate, the larger fresh sample is required to be replaced on the recent occasion.

(e) For the fixed values of $h, f_{1}, W^{*}$ and $\rho_{h, h-1}$, the values of $\mu_{h(\mathrm{opt})}$ and $L$ are almost decreasing with the increasing values of number of occasions $(h)$. This phenomenon suggests that smaller fresh sample is required on the recent occasion which leads in reducing the cost of the survey.

\section{Behavior of Estimator $\omega_{h}^{*}$}

From Table 2,

(a) For the fixed values of $h, f_{1}$, and $W^{*}$, no patterns are visible in the values of $\mu_{h(\mathrm{opt})}^{*}$ and $L^{*}$ with the increasing value of $\rho_{h, h-1}$. 
ESTIMATION OF POPULATION MEAN UNDER NON-RESPONSE

(b) For the fixed values of $h, W^{*}$, and $\rho_{h, h-1}$, the values of $\mu_{h(\mathrm{opt})}^{*}$ and $L^{*}$ are increasing with the increasing values of $f_{1}$.

(c) For the fixed values of $h, f_{1}$, and $\rho_{h, h-1}$, the values of $\mu_{h(\mathrm{opt})}^{*}$ and $L^{*}$ increase with the increasing values of $W^{*}$.

(d) For the fixed values of $f_{1}, W^{*}$ and $\rho_{h, h-1}$, the values of $\mu_{h(\mathrm{opt})}^{*}$ are decreasing while the values of $L^{*}$ are increasing with the increasing values of number of occasions $(h)$. This event suggests that smaller fresh sample is required on the recent occasion so that cost of the survey is reduced.

\section{Behavior of Estimator $\omega_{h}^{* *}$}

From Table 3,

(a) For the fixed values of $h, f_{2}$, and $W^{*}$ the values of $\mu_{h(\text { opt })}^{* *}$ and $L^{* *}$ are almost increased when the value of $\rho_{h, h-1}$ is increased.

(b) For the fixed values of $h, \rho_{h, h-1}$, and $W^{*}$ the values of $\mu_{h(\mathrm{opt})}^{* *}$ decrease while $L^{* *}$ increases with the increasing values of $f_{2}$. This phenomenon indicates that if a highly correlated auxiliary variable is available it pays in terms of reducing the cost of the survey and smaller fresh sample is required at the recent occasion.

(c) For the fixed values of $h, f_{2}$, and $\rho_{h, h-1}$, the values of $\mu_{h(\text { opt })}^{* *}$ decreases while the values of $L^{* *}$ does not follow any certain pattern with the increasing value of $W^{*}$.

(d) For the fixed values of $f_{2}, W^{*}$ and $\rho_{h, h-1}$, the values of $\mu_{h(\text { opt })}^{* *}$ and $L^{* *}$ are decreasing with the increasing values of number of occasions $(h)$. This behavior suggests that lower the non-response is useful and smaller fresh sample is required at the recent occasion which leads in the minimizing the survey cost. 


\section{SHARMA \& SINGH}

\section{Conclusion}

On the basis of preceding interpretations, it may be concluded that the proposed estimation procedure is more useful and fruitful in the estimate of population mean when non-response occur on $h^{\text {th }}$ occasion, $(h-1)^{\text {th }}$ occasion and simultaneously on both $h^{\text {th }}$ and $(h-1)^{\text {th }}$ occasions in the $h$-occasion successive sampling. It is also visible from the empirical studies that the percent relative loss

in precision is not so high. Hence, the proposed estimators $\omega_{h}, \omega_{h}^{*}$, and $\omega_{h}^{* *}$ are performing well in terms of precision even in the presence of non-responses. Thus they are reliable and may be recommended to the survey statisticians and practitioners for its practical applications.

\section{Acknowledgement}

Authors are thankful to the University Grants Commission, New Delhi and Indian School of Mines, Dhanbad for providing the financial assistance and necessary infrastructure to carry out the present work.

\section{References}

Binder, D. A., \& Hidiroglou. (1988). Sampling in Time. In P. R. Krishaiah and C. R. Rao (Eds.), Sampling (pp. 187-211). Amsterdam: North Holland.

Biradar, R. S., \& Singh, H. P. (2001). Successive sampling using auxiliary information on both occasions. Bulletin of the Calcutta Statistical Association, 51(203-204), 243-251.

Choudhary, R. K, Bathla, H. V. L., \& Sud, U. C., (2004). On non-response in sampling on two occasions. Journal of the Indian Society of Agricultural Statistics 58(3), 331-343.

Cochran, W. G. (1977). Sampling techniques ( ${ }^{\text {rd }}$ ed.). New York, NY: John Wiley \& Sons.

Eckler, A. R. (1955). Rotation sampling. The Annals of Mathematical Statistics, 26(4), 664-685. doi:10.1214/aoms/1177728427

Feng, S., \& Zou, G. (1997). Sample rotation method with auxiliary variable. Communications in Statistics - Theory and Methods, 26I6), 1497-1509. doi:10.1080/03610929708831996

Gupta, P. C. (1979). Sampling on two successive occasions. Journal of Statistical Research, 13, 7-16. 


\section{ESTIMATION OF POPULATION MEAN UNDER NON-RESPONSE}

Hansen, M. H., \& Hurwitz, W. N. (1946). The problem of the non-response in sample surveys. Journal of the American Statistical Association, 41(236), 517529. doi:10.1080/01621459.1946.10501894

Jessen, R. J. (1942). Statistical investigation of a sample survey for obtaining farm facts (No. 304). Agricultural Experiment Station, Agricultural Research Bulletins (No. 304). Ames, IA: Iowa State College.

Kish, L. (1998). Space/time variations and rolling samples. Journal of Official Statistics, 14(1), 31-46.

McLaren, C. H., \& Steel, D. G. (2000). The impact of different rotation patterns on the sampling variance of seasonally adjusted and trend estimates. Survey Methodology, 26(2), 163-172.

Okafor, F. C., \& Lee, H. (2000). Double Sampling for ratio and regression estimation with sub-sampling the non-respondents. Survey Methodology, 26(2), 183-188.

Patterson, H. D. (1950). Sampling on successive occasions with partial replacement of units. Journal of the Royal Statistical Society. Series B (Methodological), 12(2), 241-255.

Rao, J. N. K., \& Graham, J. E. (1964). Rotation design for sampling on repeated occasions. Journal of the American Statistical Association, 59(306), 492-509. doi:10.1080/01621459.1964.10482175

Sen, A. R. (1971). Successive sampling with two auxiliary variables. Sankhyā: The Indian Journal of Statistics, Series B (1960-2002), 33(3/4), 371-378.

Sen, A. R. (1973). 346. Note: Theory and application of sampling on repeated occasions with several auxiliary variables. Biometrics, 29(2), 381-385. doi:10.2307/2529401

Singh, A. C., Kennedy, B. \& Wu, S. (2001). Regression composite estimation for the Canadian labour force survey with a rotating panel design. Survey Methodology, 27(1), 33-44.

Singh, G. N. (2003). Estimation of population mean using auxiliary information on recent occasion in h occasions successive sampling. Statistics in Transition, 6(4), 523-532.

Singh, G. N. (2005). On the use of chain-type ratio estimator in successive sampling. Statistics in Transition, 7(1), 21-26.

Singh, G. N., \& Karna, J. P. (2009). Estimation of population mean on current occasion in two-occasion successive sampling. Metron, 67(1), 87-103. 


\section{SHARMA \& SINGH}

Singh, G. N., Majhi, D., Maurya, S., \& Sarma, A. K. (2015). Some effective rotation patterns in estimation of population mean in two-occasion successive sampling. Communications in Statistics - Theory \& Methods, 44(12), 2571-2585. doi:10.1080/03610926.2013.785000.

Singh, G. N., \& Prasad, S. (2010). Some estimators of population mean in two occasions rotation patterns. Advances in Modelling. Series A. General Mathematics, 47(2), 1-18.

Singh, G. N., Prasad, S., \& Karna, J. P. (2011). Some classes of estimators for population mean at current occasion in two-occasion successive sampling, Journal of Statistical Research, 45(1), 21-36.

Singh, G. N., \& Priyanka, K. (2007). Effect of non-response on current occasion in search of good rotation patterns on successive occasions. Statistics in Transition-New Series, 8(2), 273-292.

Singh, G. N., \& Sharma, A. K. (2014). An alternative rotation patterns in two occasion successive sampling. International Journal of Mathematics and Statistics, 15(3), 9-22.

Singh, G. N., \& Sharma, A. K. (2015). Search of some effective rotation patterns in estimation of population mean on current occasion in two-occasion successive sampling. Journal of Statistics Application and Probability, 4(1), 127 138.

Singh, G. N., \& Singh, V. K. (2001). On the use of auxiliary information in successive sampling. Journal of the Indian Society of Agricultural Statistics, 54(1), $1-12$.

Singh, H. P., \& Kumar, S. (2008). A regression approach to the estimation of finite population mean in the presence of non-response. Australian \& New Zealand Journal of Statistics, 50(4), 395-408.

doi:10.1111/j.1467-842X.2008.00525.x

Singh, V. K., Singh, G. N., \& Shukla, D. (1991). An efficient family of ratio-cum-difference type estimators in successive sampling over two occasions. Journal of Scientific Research, 41 C, 149-159.

Steel D. G., \& McLaren, C. H. (2002). In search of good rotation pattern. Submitted to world Scientific.

Sukhatme, P. V., Sukhatme, B. V., Sukhatme, S. \& Asok, C. (1984). Sampling theory of surveys with applications ( $3^{\text {rd }}$ revised ed.). Ames, IA: Iowa State University Press. 


\section{ESTIMATION OF POPULATION MEAN UNDER NON-RESPONSE}

Tikkiwal, B. D. (1951). Theory of successive sampling (Unpublished dissertation). Institute of Agricultural Research Statistics, New Delhi, India.

Yates, F. (1949). Sampling methods for census and surveys. London: Charles Griffin and Company Limited. 